\title{
Identification of Genomic Alterations Acquired During Treatment With EGFR-TKIs in Non-small Cell Lung Cancer
}

\author{
NAOKI KUBO ${ }^{1,2^{*}}$, TAISHI HARADA ${ }^{1,3}$, YOSHIMASA SHIRAISHI ${ }^{1,4}$, KANAME NOSAKI $^{5}$, \\ NORIAKI NAKAGAKI ${ }^{6}$, MASAFUMI TAKESHITA $^{7}$, HIROSHI OUCHI $^{3}$, EIJI IWAMA ${ }^{1}$, \\ KENTARO TANAKA ${ }^{1}$, ISAMU OKAMOTO ${ }^{1}$, HIROYUKI SASAKI ${ }^{2}$ and YOICHI NAKANISHI ${ }^{1}$ \\ ${ }^{1}$ Research Institute for Diseases of the Chest, Graduate School of Medical Sciences, \\ Kyushu University, Fukuoka, Japan; \\ ${ }^{2}$ Division of Epigenomics and Development, Medical Institute of Bioregulation, Kyushu University, Fukuoka, Japan; \\ ${ }^{3}$ Department of Respiratory Medicine, JCHO Kyushu Hospital, Fukuoka, Japan; \\ ${ }^{4}$ Department of Respiratory Medicine, National Hospital Organization \\ Fukuoka-Higashi Medical Center, Fukuoka, Japan; \\ ${ }^{5}$ Department of Thoracic Oncology, National Hospital Organization Kyushu Cancer Center, Fukuoka, Japan; \\ ${ }^{6}$ Department of Respiratory Medicine, Steel Memorial Yawata Hospital, Fukuoka, Japan; \\ ${ }^{7}$ Department of Respiratory Medicine, Kitakyushu Municipal Medical Center, Fukuoka, Japan
}

671Abstract. Background/Aim: Patients with non-small cell lung cancer (NSCLC) treated with epidermal growth factor receptor (EGFR) tyrosine kinase inhibitors (TKIs) eventually develop resistance to these drugs. Although various mechanisms of such resistance have been identified, the mechanism in many cases remains unknown. Materials and Methods: Whole-exome sequencing was performed for tumor tissue from 15 patients with NSCLC who developed EGFRTKI resistance. Tumor specimens obtained before EGFR-TKI treatment were also analyzed for four patients and normal white blood cell samples for six patients in order to detect genomic alterations that occurred during treatment. Results: The mutational signature and mutational load acquired during EGFR-TKI treatment varied among patients, with common EGFR-TKI resistance mechanisms including the T790M secondary mutation of EGFR and MET amplification being acquired together with many other genomic alterations. Our results provide insight into the mutational landscape acquired during the development of EGFR-TKI resistance in NSCLC.

\footnotetext{
*Present address: Ludwig Institute for Cancer Research, University of California at San Diego School of Medicine, La Jolla, California 92093, USA.

Correspondence to: Taishi Harada, MD, Ph.D., Research Institute for Diseases of the Chest, Kyushu University, 3-1-1 Maidashi, Higashi-ku, Fukuoka 812-8582, Japan. E-mail: harada-t@kokyu.med.kyushu-u.ac.jp

Key Words: Non-small cell lung cancer, EGFR-TKI, exome sequencing, genomic mutation, drug resistance.
}

The development of cancer is governed by the accumulation of many somatic genetic alterations, some of which are driver mutations $(1,2)$. Recent advances in biomedical research have provided important insight into the molecular basis of cancer and have led to breakthroughs in therapeutic interventions (3-5). Mutations in the epidermal growth factor receptor $(E G F R)$ gene and rearrangements of the anaplastic lymphoma kinase $(A L K)$ gene that result in constitutive upregulation of the tyrosine kinase activity of the encoded proteins have been identified as drivers of non-small cell lung cancer (NSCLC). Tyrosine kinase inhibitors (TKIs) that target these mutant kinases-including gefitinib (5) and erlotinib (6) for EGFR, and crizotinib for $\operatorname{ALK}(3,7)$, have shown marked efficacy for the treatment of NSCLC positive for the corresponding genetic alterations, with treatment decisions being currently based on testing for these genetic changes $(8,9)$. However, all patients with NSCLC who are initially sensitive to TKIs eventually develop resistance to these drugs that is mediated by various mechanisms (10-13).

Well-characterized mechanisms underlying the resistance of NSCLC to EGFR-TKIs include the T790M secondary mutation of EGFR (11-13); the activation of alternative signaling pathways mediated by amplification of MET protooncogene, receptor tyrosine kinase (MET) or overexpression of human epidermal growth factor receptor (HER) family proteins $(14,15)$; aberrant downstream signaling of EGFR mediated by KRAS proto-oncogene, GTPase (KRAS) mutation or loss of phosphatase and tensin homolog (PTEN) (16-18); EGFR-TKI-induced apoptosis associated with Bcl2 like 11 (BCL2L11) deletion polymorphism (19); and transformation to small cell carcinoma $(20,21)$. Although the 
T790M secondary mutation of EGFR is rarely present before EGFR-TKI treatment, it has been detected in about half of such treated patients. Detection of this mutation has, thus, become an important determinant of treatment strategies, such as the administration of third-generation EGFR-TKIs that target EGFRT790M (21-24), and attempts are underway to develop additional agents to overcome EGFR-TKI resistance (24-26). Despite the identification of various mechanisms of EGFR-TKI resistance, in many cases they remain obscure. Furthermore, genomic alterations that might occur in addition to the characterized resistance-conferring changes are largely unknown. For example, it remains unclear whether other genetic changes accompany the appearance of the T790M secondary mutation of EGFR and, if so, whether such additional changes occur selectively with the T790M mutation or also accompany the genetic alterations underlying other resistance mechanisms.

The recent development of next-generation sequencing (NGS) technology has allowed the identification of somatic mutations at the whole-genome level. Whole-exome sequencing (WES), in which captured coding regions of the genome are subjected to sequencing, is a cost-effective method for the detection of disease-causing variants and discovery of drug targets. In order to characterize further the mechanisms of acquired resistance to targeted therapy in NSCLC, we performed WES on tumor DNA from patients with NSCLC with acquired resistance to EGFR-TKIs.

\section{Materials and Methods}

Patients and specimens. Fifteen Japanese patients with NSCLC were included in the study. All patients were enrolled and examined between January 2013 and December 2015 and were treated daily with either erlotinib or gefitinib. Patient specimens were collected and studied with the approval of the Ethical Review Board for Human Genome/Gene Research at each participating institute. Informed consent was obtained from all participants. In four patients (cases 1-4), cancer specimens were obtained both before EGFR-TKI treatment and after treatment failure. In six patients (cases 5-10), cancer specimens obtained after EGFR-TKI treatment failure as well as normal white blood cell (WBC) samples were analyzed. In the five remaining patients (cases 11-15), only cancer specimens obtained after EGFR-TKI treatment failure were studied.

WES library preparation and sequencing. Genomic DNA was extracted from each specimen, and libraries were generated with the use of a SureSelect XT Human All Exon V5+lncRNA enrichment kit (Agilent, Santa Clara, CA, USA). The libraries were sequenced on an Illumina HiSeq 2000 instrument to generate 100- or 133nucleotide paired-end reads for each sample.

WES analysis. High-quality reads were obtained after trimming the low-quality bases from the 3 ' end and the adapter sequences from the 5 ' end with the use of the NGS QC Toolkit (27). The resulting reads were aligned to the reference human genome (hg19) (28) with the use of the Burrows-Wheeler Aligner (29). The alignment information was stored in BAM format files, and duplications were marked with the use of Picard (http://broadinstitute.github.io/picard). Realignment and recalibration were performed to obtain reliable alignment results with the use of Genome Analysis Toolkit (GATK) (30).

Somatic single-nucleotide variations (SNVs) in TKI-resistant tumors, TKI-sensitive tumors, and WBCs were detected with GATK. De novo SNVs were selected by subtraction of those identified in TKIsensitive tumors or WBCs from those identified in TKI-resistant tumors. A series of filters was then applied to define SNVs. For somatic mutations, the mutant allelic frequency had to be $\geq 10 \%$ and mutations with low base quality $(<20)$ or low mapping quality $(<20)$ were discarded. Other thresholds for determination of somatic point mutations included a sequencing depth for both tumor and matched normal sample of $\geq 20$, a distance between two adjacent mutations of $\geq 10 \mathrm{bp}$, and occurrence outside of simple repeat regions. Allelic frequencies in the Exome Aggregation Consortium data (http:// exac.broadinstitute.org), Exome Sequencing Project 6500 data (http://evs.gs.washington.edu/EVS), and The Human Genetic Variation Database (http://www.genome.med.kyoto-u.ac.jp/SnpDB) had to be $\leq 0.1 \%$. SNVs that overlapped with single-nucleotide polymorphisms in dbSNP version 138 (31) were also removed. Nonsynonymous missense mutations called by WES were evaluated with SIFT (http://sift.jcvi.org) and Polyphen2 (http://genetics.bwh.harvard.edu/ $\mathrm{pph} 2$ ) for their potential impact on protein function. Mutect was also used with default options (32) to detect de novo SNVs in cases 1 to 10. The SomaticIndelDetector tool included in GATK was used to detect de novo insertions-deletions (indels) by comparison of specimens as described above, with the command for filtering option being "T_COV $<20 \| N$ NOV $<10 \|$ T_INDEL_F $<0.1 \| T$ INDEL_CF $<0.7$." ANNOVAR (33) was used to annotate the variant results, and EXCAVATOR (34) was used to detect copy number variants (CNVs) by comparison of TKI-resistant tumors with control samples (TKIsensitive tumors or WBCs).

Data availability. Sequencing data have been deposited under the accession number JGAS00000000102 in the Japanese GenotypePhenotype Archive (JGA, http://trace.ddbj.nig.ac.jp/jga).

\section{Results}

Clinical characteristics of the study patients. All patients were Japanese and included 10 women and five men with an age range of 47 to 79 years (Table I). Ten patients $(66.7 \%)$ were never-smokers and five $(33.3 \%)$ were former smokers. Twelve patients had stage IV adenocarcinoma and the remaining three had recurrent adenocarcinoma at the start of EGFR-TKI therapy. Eight patients were treated with gefitinib, and seven received erlotinib. The median duration of EGFR-TKI therapy was 347 days, ranging from 80 to 2,557 days. Cancer specimens were obtained after EGFRTKI treatment failure for all patients. Cancer specimens were also obtained by biopsy before TKI treatment in four patients (cases 1-4), and WBCs were obtained in six patients after TKI treatment (cases 5-10) as control samples.

Mutational signatures. The most frequent base substitution was C-to-T (G-to-A) in all tumor specimens of the study patients, with the second most frequent being A-to-G 
(T-to-C) with the exception of EGFR-TKI-resistant specimens in cases 1 and 8 (Figure 1). Hydrolytic deamination of cytosine or 5-methylcytosine $(5 \mathrm{mC})$ results in C-to- $\mathrm{U}$ and 5mC-to-T mutations, respectively, with subsequent misrepair leading to replacement of uracil with thymine and a consequent $\mathrm{C}$-to- $\mathrm{T}$ transition. Frequent $5 \mathrm{mC}$-to- $\mathrm{T}$ substitutions were previously implicated in the appearance of the T790M (ACG $\rightarrow$ ATG) mutation of EGFR (35). The C-to$\mathrm{T}$ mutation was also previously found be strongly positively correlated with age (1), which is consistent with the age range (47 to 79 years) of the patients in the present study. The point mutations acquired during EGFR-TKI treatment varied among patients. For example, C-to-T and C-to-A mutations increased markedly during EGFR-TKI treatment in cases 1 and 2 but not in cases 3 and 4 (Figure 1). Patients 1 and 2 were never-smokers, suggesting that some other stress that induces point mutations at such sites might be related to EGFR-TKI resistance.

T790M mutation of EGFR and MET amplification are accompanied by a large number of additional mutations. The EGFR mutations detected before TKI treatment are shown in Table I. All patients had NSCLC positive for activating mutations of $E G F R$, with nine and six patients harboring exon 19 deletions and L858R in exon 21, respectively. The TKI resistance-conferring T790M mutation in exon 20 was detected in four patients (cases 1, 4, 11, and 15) after treatment failure, and was also detected before treatment initiation in case 4 . We also detected a large number of $\mathrm{CNV}$ candidates in the patients (cases 1-10) for whom control specimens were available (Table I). MET amplification, another common mechanism of EGFR-TKI resistance, was detected in two patients (cases 2 and 8) (Table I).

Comparison of WES data for tumor specimens obtained before EGFR-TKI treatment and after development of resistance in cases 1 to 4 allowed the identification of genomic alterations acquired during treatment. The number of de novo SNVs detected in cases 1 and 2 was high (117 and 50 genes, respectively), whereas that in cases 3 and 4 was low ( 0 and 1 gene, respectively) (Table I). In case 4 , the T790M mutation was already present before treatment onset. The number of de novo indels in cases 1 to 4 was relatively low at 2 to 7 , and none of these indels was present in more than one of these patients [an indel in zinc finger and SCAN domain containing 18 (ZSCAN18) was detected in cases 3 and 8] (Table I). The number of CNV candidate regions was especially large in case 2 , with this patient also being positive for MET amplification (Table I).

For cases 5 to 10 , in which cancer specimens obtained after the development of EGFR-TKI resistance were compared with normal WBC samples to identify genomic alterations acquired before treatment failure, the number of genomic alterations also varied. The numbers of de novo

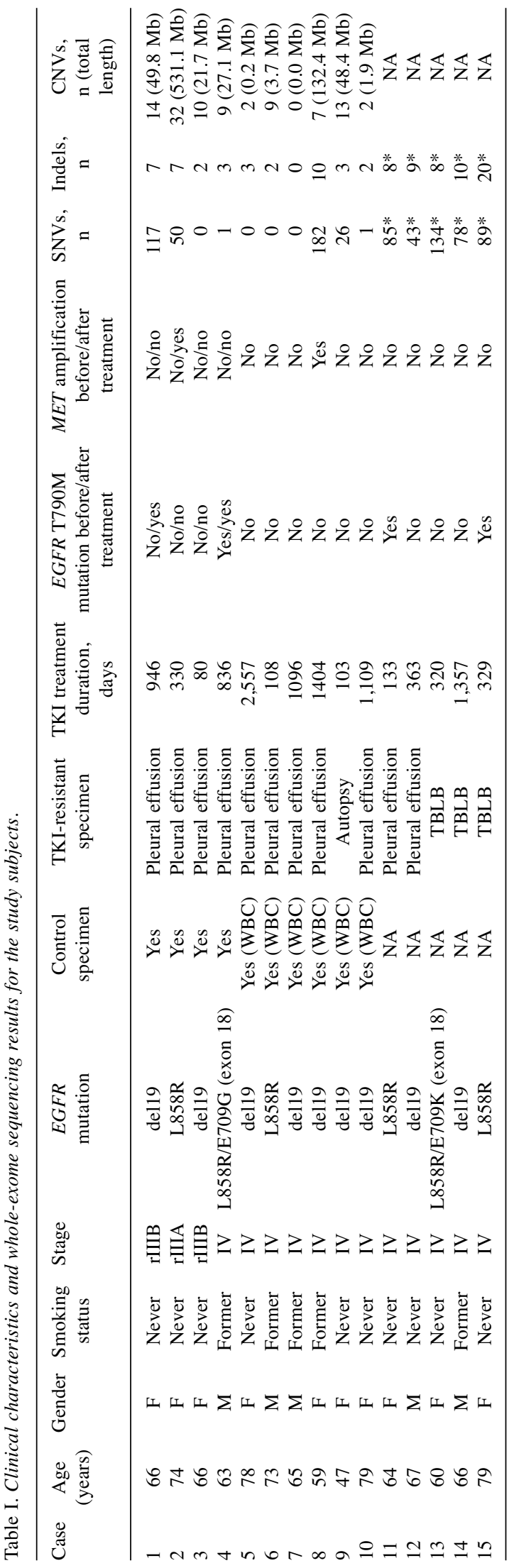

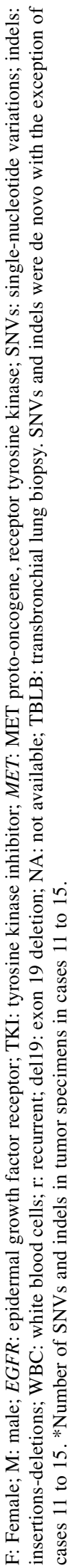




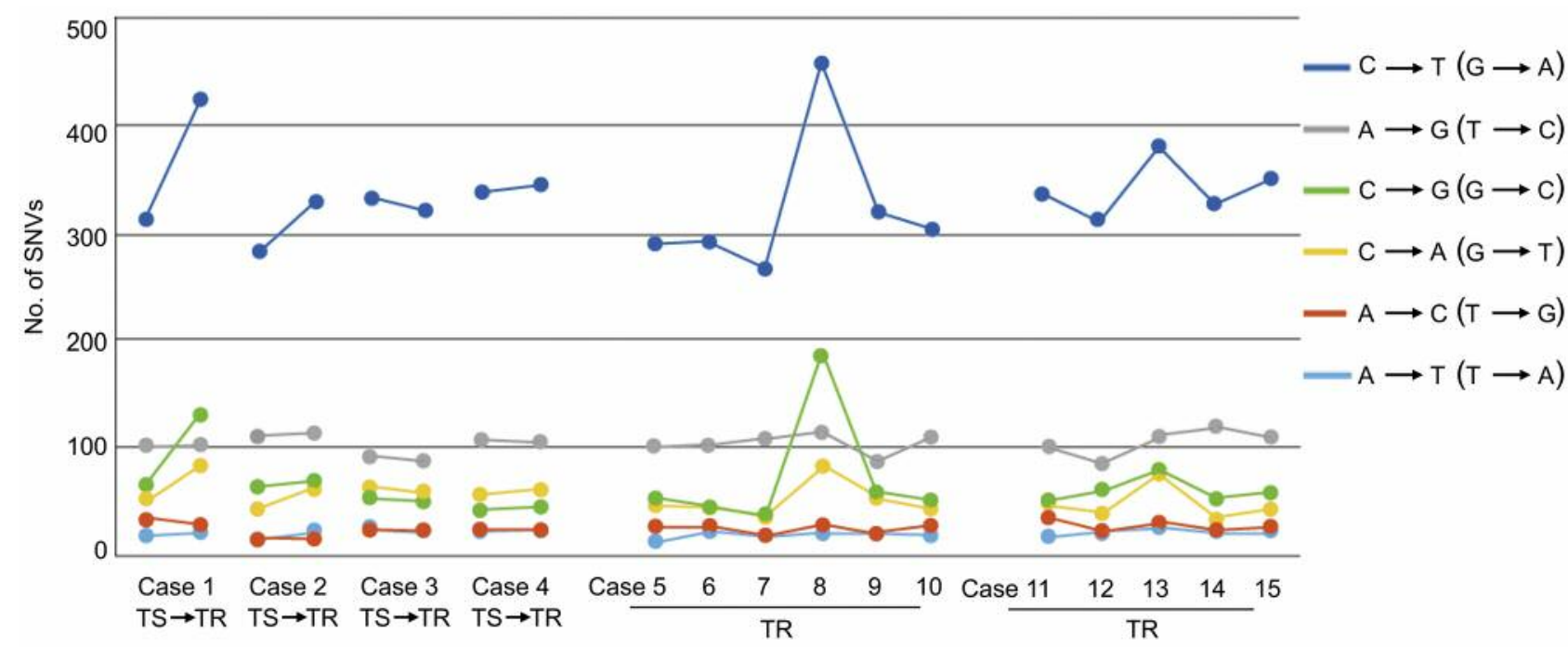

Figure 1. Mutational signatures. The number of single-nucleotide variations (SNVs), including synonymous substitutions, in tumors of the study patients is plotted. The most frequent base substitution was C-to-T (G-to-A) in all 15 cases, and the second most frequent mutation was A-to-G (Tto-C) with the exception of the tyrosine kinase inhibitor(TKI)-resistant (TR) tumors of cases 1 and 8. TS: TKI-sensitive.

SNVs and indels in case 8 were high (182 and 10 genes, respectively), with the number of genomic alterations identified in the other cases being low (0-26 SNVs and 0-3 indels) (Table I). The number of genes located in CNV regions was also high in case $8(1,109$ genes) and included MET (Table I).

The variable mutational load and our relatively small sample size made it difficult to identify candidate genes that might be the cause of EGFR-TKI resistance with statistical significance. We, therefore, referred to previous studies that analyzed mutations in EGFR-TKI-resistant tumor specimens $(36,37)$ in order to identify overlapping mutated genes among the studies and examine similarity in variability of mutational load. Although both previous studies lacked EGFR-TKI-sensitive specimens as controls, they detected a variable mutational load among the cases, and some of the genes with SNVs overlapped with those in our data set.

The T790M secondary mutation of EGFR or MET amplification were identified in cases 1,2 , and 8 , with these patients having a high mutational load, suggesting that these frequent EGFR-TKI resistance mutations are acquired together with a large number of additional genomic alterations. Gene ontology analysis of genes affected by SNVs in cases 1 and 2 with the Database for Annotation, Visualization, and Integrated Discovery tool (38) identified terms such as "Cell adhesion" and "Pathways in cancer". With regard to the relation between mutational load and duration of EGFR-TKI treatment, for cases with a high mutational load ( $\geq 25$ de novo SNVs;

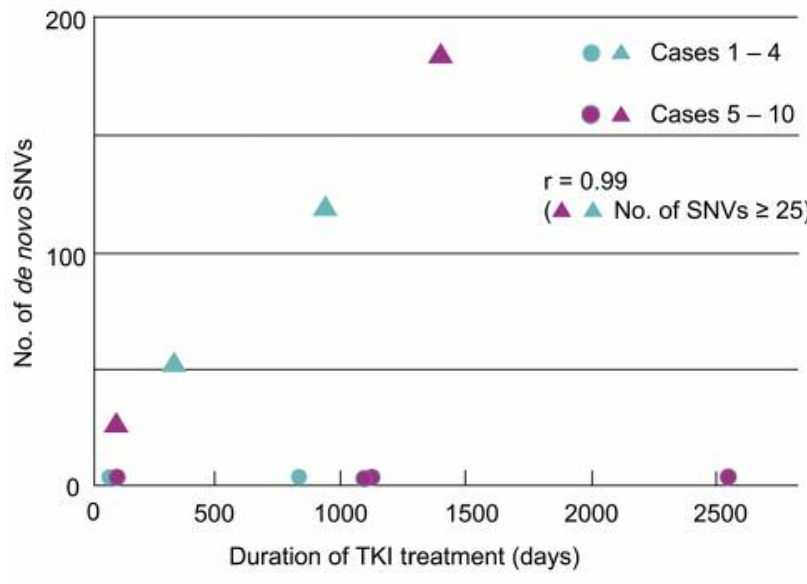

Figure 2. Duration of epidermal growth factor receptor (EGFR) tyrosine kinase inhibitor (TKI) treatment and mutational load. The number of de novo single-nucleotide variations (SNVS) and the duration of EGFR-TKI treatment for cases 1 to 10 are shown in a scatter plot. Cases with a high mutational load are indicated by triangles $(\geq 25$ de novo SNVs; cases 1 , 2,8 , and 9) and the number of de novo SNVs was positively correlated with the duration of TKI treatment $(r=0.99)$. On the other hand, cases with a low mutational load are indicated by circles $(\leq 2$ de novo SNVs; cases 3-7 and 10) and showed various durations of TKI treatment.

cases 1, 2, 8, and 9) the number of SNVs tended to be positively correlated with the duration of TKI treatment $(r=0.99)$ (Figure 2). In contrast, other cases continued to show a low mutational load even after long-term TKI treatment ( $>500$ days). 


\section{Discussion}

EGFR-TKI resistance is a pressing clinical problem in the treatment of NSCLC, with the identification of resistance mechanisms being essential for the development of new strategies to overcome treatment failure. The next generation of EGFR-TKIs and specific antibodies to related molecules are under development (39-41), but further characterization of the mechanisms of EGFR-TKI resistance is needed. In the present study, we performed WES on clinical specimens of patients with NSCLC who underwent a second biopsy after failure of EGFR-TKI treatment. We identified de novo genomic alterations acquired during EGFR-TKI treatment by comparing these WES data with those obtained for tumor specimens collected before TKI treatment or for WBC samples.

The mutational signatures of the cancer specimens showed several similarities and differences. The predominant base substitution was C-to-T (G-to-A), with the C-to-A (G-to-T) mutation, which is prominent in smoking-associated cancer (1), being relatively infrequent in all cases. However, both C-to-T and C-to-A mutation frequencies increased during EGFR-TKI treatment in cases 1 and 2, which acquired the T790M mutation of EGFR and MET amplification, respectively. These mutation frequencies did not change substantially during EGFR-TKI treatment in cases 3 and 4, suggesting that a specific endogenous or exogenous stressor that induces $\mathrm{C}$-to- $\mathrm{T}$ and $\mathrm{C}$-to- $\mathrm{A}$ mutations might be associated with these common TKI resistance mechanisms.

The frequencies of genomic alterations varied among cases, with the T790M mutation of EGFR and MET amplification occurring together with a large number of other mutations. Given the high frequency of these EGFR-TKI resistance mutations, it might be expected that they occur preferentially without multiple other mutations during EGFR-TKI treatment. However, we identified multiple mutations in addition to T790M of EGFR or MET amplification in two cases (cases 1 and 2), whereas fewer mutations were detected in patients who did not develop these common resistance mechanisms during EGFR-TKI treatment (cases 3 and 4).

Nivolumab, an antibody to the programmed cell death-1 immune-checkpoint protein, is a recent breakthrough in NSCLC therapy, with clinical studies having suggested that both former and current smokers respond well to this agent (42). One potential explanation for this latter finding is that smoking-associated lung cancer is associated with a high mutational load that may lead to the production of a greater number of tumor neoantigens and increased tumor immunogenicity. In the present study, we found that the mutational load differed among patients with various mechanisms of TKI resistance. Cases 1 and 2, for example, which acquired the T790M mutation of EGFR and MET amplification, respectively, showed a high mutational load, whereas cases 3 and 4, for which a well-characterized mechanism of TKI resistance was not identified, had a low mutational load. The efficacy of nivolumab for patients with NSCLC who have experienced EGFR-TKI treatment failure might thus differ depending on the mechanism of TKI resistance. Among cases 11 to 15, however, for which only cancer specimens obtained after the development of EGFR-TKI resistance were available, the number of SNVs in cases 11 and 15, which were positive for the T790M mutation of EGFR, was not substantially higher than that in the cases without this mutation. Although we were not able to identify de novo mutations acquired during EGFRTKI treatment for cases 11 to 15 because of the lack of control specimens, these results suggest that the T790M mutation might not always be associated with a high mutational load, as in cases 1 and 2. A larger patient population will thus be necessary to reveal statistically significant associations among genomic alterations acquired during EGFR-TKI treatment. Another limitation of our study is the variability in sampling sites. Most of the cancer specimens obtained after failure of EGFR-TKI treatment comprised pleural effusion and differed from those obtained before treatment. It is possible that the type of biopsy specimen might affect the accuracy of mutation detection. The adoption of strict sampling criteria is thus warranted in future studies.

Our WES-based study has, thus, identified somatic mutations acquired during EGFR-TKI treatment and revealed a variable mutational load among patients. A high mutational load was preferentially identified in patients with common EGFR-TKI resistance mechanisms including the T790M mutation of EGFR and MET amplification. Furthermore, among those tumors with a high mutational load, C-to-T and C-to-A mutation frequencies increased during EGFR-TKI treatment. Our data will serve as an important resource for future studies and may facilitate further efforts to identify novel mechanisms of EGFR-TKI resistance and improve therapeutic options for patients with NSCLC.

\section{Conflicts of Interest}

K.N. has received research funding from MSD and Novartis Pharma as well as honoraria from AstraZeneca, Chugai Pharmaceutical, Eli Lilly Japan, Kyowa Hakko Kirin, Nippon Boehringer Ingelheim, Nippon Kayaku, and Ono Pharmaceutical. All other Authors declare no conflicts of interest in regard to this study.

\section{Acknowledgements}

This study was funded by a research program of the Project for Development of Innovative Research on Cancer Therapeutics (PDIRECT) of the Ministry of Education, Culture, Sports, Science, and Technology of Japan. 


\section{References}

1 Alexandrov LB, Nik-Zainal S, Wedge DC, Aparicio SA, Behjati S, Biankin AV, Bignell GR, Bolli N, Borg A, Børresen-Dale AL, Boyault S, Burkhardt B, Butler AP, Caldas C, Davies HR, Desmedt C, Eils R, Eyfjörd JE, Foekens JA, Greaves M, Hosoda F, Hutter B, Ilicic T, Imbeaud S, Imielinski M, Imielinsk M, Jäger N, Jones DT, Jones D, Knappskog S, Kool M, Lakhani SR, López-Otín C, Martin S, Munshi NC, Nakamura H, Northcott PA, Pajic M, Papaemmanuil E, Paradiso A, Pearson JV, Puente XS, Raine K, Ramakrishna M, Richardson AL, Richter J, Rosenstiel P, Schlesner M, Schumacher TN, Span PN, Teague JW, Totoki Y, Tutt AN, Valdés-Mas R, van Buuren MM, van 't Veer L, Vincent-Salomon A, Waddell N, Yates LR, Australian Pancreatic Cancer Genome Initiative, ICGC Breast Cancer Consortium, ICGC MMML-Seq Consortium, ICGC PedBrain, Zucman-Rossi J, Futreal PA, McDermott U, Lichter P, Meyerson M, Grimmond SM, Siebert R, Campo E, Shibata T, Pfister SM, Campbell PJ and Stratton MR: Signatures of mutational processes in human cancer. Nature 500(7463): 415-421, 2013.

2 Stratton MR, Campbell PJ and Futreal PA: The cancer genome. Nature 458(7239): 719-724, 2009.

3 Soda M, Choi YL, Enomoto M, Takada S, Yamashita Y, Ishikawa S, Fujiwara S, Watanabe H, Kurashina K, Hatanaka H, Bando M, Ohno S, Ishikawa Y, Aburatani H, Niki T, Sohara Y, Sugiyama $\mathrm{Y}$ and Mano H: Identification of the transforming $E M L 4-A L K$ fusion gene in non-small-cell lung cancer. Nature 448(7153): 561-566, 2007.

4 Torti D and Trusolino L: Oncogene addiction as a foundational rationale for targeted anti-cancer therapy: Promises and perils. EMBO Mol Med 3(11): 623-636, 2011.

5 Thatcher N, Chang A, Parikh P, Rodrigues Pereira J, Ciuleanu T, von Pawel J, Thongprasert S, Tan EH, Pemberton K, Archer $\mathrm{V}$ and Carroll K: Gefitinib plus best supportive care in previously treated patients with refractory advanced non-smallcell lung cancer: Results from a randomised, placebo-controlled, multicentre study (Iressa Survival Evaluation in Lung Cancer). Lancet 366(9496): 1527-1537, 2005.

6 Shepherd FA, Rodrigues Pereira J, Ciuleanu T, Tan EH, Hirsh V, Thongprasert S, Campos D, Maoleekoonpiroj S, Smylie M, Martins R, van Kooten M, Dediu M, Findlay B, Tu D, Johnston D, Bezjak A, Clark G, Santabárbara P, and Seymour L for the National Cancer Institute of Canada Clinical Trials Group: Erlotinib in previously treated non-small-cell lung cancer. N Engl J Med 353(2): 123-132, 2005.

7 Bronte G, Rizzo S, La Paglia L, Adamo V, Siragusa S, Ficorella C, Santini D, Bazan V, Colucci G, Gebbia N and Russo A: Driver mutations and differential sensitivity to targeted therapies: A new approach to the treatment of lung adenocarcinoma. Cancer Treat Rev 36(Suppl 3): S21-29, 2010.

8 Mitsudomi T and Yatabe Y: Mutations of the epidermal growth factor receptor gene and related genes as determinants of epidermal growth factor receptor tyrosine kinase inhibitors sensitivity in lung cancer. Cancer Sci 98(12): 1817-1824, 2007.

9 Kwak EL, Bang YJ, Camidge DR, Shaw AT, Solomon B, Maki RG, Ou SH, Dezube BJ, Jänne PA, Costa DB, Varella-Garcia M, Kim WH, Lynch TJ, Fidias P, Stubbs H, Engelman JA, Sequist LV, Tan W, Gandhi L, Mino-Kenudson M, Wei GC, Shreeve SM, Ratain MJ, Settleman J, Christensen JG, Haber DA, Wilner K, Salgia R, Shapiro GI, Clark JW and Iafrate AJ: Anaplastic lymphoma kinase inhibition in non-small-cell lung cancer. $\mathrm{N}$ Engl J Med 363(18): 1693-1703, 2010.

10 Yu HA, Riely GJ and Lovly CM: Therapeutic strategies utilized in the setting of acquired resistance to EGFR tyrosine kinase inhibitors. Clin Cancer Res 20(23): 5898-5907, 2014.

11 Yu HA, Arcila ME, Rekhtman N, Sima CS, Zakowski MF, Pao W, Kris MG, Miller VA, Ladanyi M and Riely GJ: Analysis of tumor specimens at the time of acquired resistance to EGFR-TKI therapy in 155 patients with EGFR-mutant lung cancers. Clin Cancer Res 19(8): 2240-2247, 2013.

12 Kobayashi S, Boggon TJ, Dayaram T, Jänne PA, Kocher O, Meyerson M, Johnson BE, Eck MJ, Tenen DG and Halmos B: EGFR mutation and resistance of non-small-cell lung cancer to gefitinib. N Engl J Med 352(8): 786-792, 2005.

13 Ohashi K, Maruvka YE, Michor F and Pao W: Epidermal growth factor receptor tyrosine kinase inhibitor-resistant disease. J Clin Oncol 31(8): 1070-1080, 2013.

14 Landi L and Cappuzzo F: HER2 and lung cancer. Expert Rev Anticancer Ther 13(10): 1219-1228, 2013.

15 Engelman JA, Zejnullahu K, Mitsudomi T, Song Y, Hyland C, Park JO, Lindeman N, Gale CM, Zhao X, Christensen J, Kosaka T, Holmes AJ, Rogers AM, Cappuzzo F, Mok T, Lee C, Johnson BE, Cantley LC and Jänne PA: MET amplification leads to gefitinib resistance in lung cancer by activating ERBB3 signaling. Science 316(5827): 1039-1043, 2007.

16 Pao W, Wang TY, Riely GJ, Miller VA, Pan Q, Ladanyi M, Zakowski MF, Heelan RT, Kris MG and Varmus HE: KRAS mutations and primary resistance of lung adenocarcinomas to gefitinib or erlotinib. PLoS Med 2(1): e17, 2005.

17 Sos ML, Koker M, Weir BA, Heynck S, Rabinovsky R, Zander T, Seeger JM, Weiss J, Fischer F, Frommolt P, Michel K, Peifer M, Mermel C, Girard L, Peyton M, Gazdar AF, Minna JD, Garraway LA, Kashkar H, Pao W, Meyerson M and Thomas RK: PTEN loss contributes to erlotinib resistance in EGFRmutant lung cancer by activation of AKT and EGFR. Cancer Res 69(8): 3256-3261, 2009.

18 Bidkhori G, Moeini A and Masoudi-Nejad A: Modeling of tumor progression in NSCLC and intrinsic resistance to TKI in loss of PTEN expression. PLoS One 7(10): e48004, 2012.

19 Ng KP, Hillmer AM, Chuah CT, Juan WC, Ko TK, Teo AS, Ariyaratne PN, Takahashi N, Sawada K, Fei Y, Soh S, Lee WH, Huang JW, Allen JC, Woo XY, Nagarajan N, Kumar V, Thalamuthu A, Poh WT, Ang AL, Mya HT, How GF, Yang LY, Koh LP, Chowbay B, Chang CT, Nadarajan VS, Chng WJ, Than H, Lim LC, Goh YT, Zhang S, Poh D, Tan P, Seet JE, Ang MK, Chau NM, Ng QS, Tan DS, Soda M, Isobe K, Nöthen MM, Wong TY, Shahab A, Ruan X, Cacheux-Rataboul V, Sung WK, Tan EH, Yatabe Y, Mano H, Soo RA, Chin TM, Lim WT, Ruan $\mathrm{Y}$ and Ong ST: A common BIM deletion polymorphism mediates intrinsic resistance and inferior responses to tyrosine kinase inhibitors in cancer. Nat Med 18(4): 521-528, 2012.

20 Alam N, Gustafson KS, Ladanyi M, Zakowski MF, Kapoor A, Truskinovsky AM and Dudek AZ: Small-cell carcinoma with an epidermal growth factor receptor mutation in a never-smoker with gefitinib-responsive adenocarcinoma of the lung. Clin Lung Cancer 11(5): E1-4, 2010.

21 Sequist LV, Waltman BA, Dias-Santagata D, Digumarthy S, Turke AB, Fidias P, Bergethon K, Shaw AT, Gettinger S, Cosper AK, Akhavanfard S, Heist RS, Temel J, Christensen JG, Wain JC, Lynch TJ, Vernovsky K, Mark EJ, Lanuti M, Iafrate AJ, 
Mino-Kenudson $M$ and Engelman JA: Genotypic and histological evolution of lung cancers acquiring resistance to EGFR inhibitors. Sci Transl Med 3(75): 75ra26, 2011.

22 Yu HA and Pao W: Targeted therapies: Afatinib - new therapy option for EGFR-mutant lung cancer. Nat Rev Clin Oncol 10(10): 551-552, 2013.

23 Wang S, Cang S and Liu D: Third-generation inhibitors targeting EGFR $\mathrm{t} 790 \mathrm{~m}$ mutation in advanced non-small cell lung cancer. J Hematol Oncol 9: 34, 2016.

24 Chong CR and Jänne PA: The quest to overcome resistance to EGFR-targeted therapies in cancer. Nat Med 19(11): 1389-1400, 2013.

25 Jia Y, Yun CH, Park E, Ercan D, Manuia M, Juarez J, Xu C, Rhee K, Chen T, Zhang H, Palakurthi S, Jang J, Lelais G, DiDonato M, Bursulaya B, Michellys PY, Epple R, Marsilje TH, McNeill M, Lu W, Harris J, Bender S, Wong KK, Jänne PA and Eck MJ: Overcoming $E G F R(\mathrm{~T} 790 \mathrm{M})$ and $E G F R(\mathrm{C} 797 \mathrm{~S})$ resistance with mutant-selective allosteric inhibitors. Nature 534(7605): 129-132, 2016

26 Walter AO, Sjin RT, Haringsma HJ, Ohashi K, Sun J, Lee K, Dubrovskiy A, Labenski M, Zhu Z, Wang Z, Sheets M, St Martin T, Karp R, van Kalken D, Chaturvedi P, Niu D, Nacht M, Petter RC, Westlin W, Lin K, Jaw-Tsai S, Raponi M, Van Dyke T, Etter J, Weaver Z, Pao W, Singh J, Simmons AD, Harding TC and Allen A: Discovery of a mutant-selective covalent inhibitor of EGFR that overcomes T790M-mediated resistance in NSCLC. Cancer Discov 3(12): 1404-1415, 2013.

27 Patel RK and Jain M: NGS QC toolkit: A toolkit for quality control of next-generation sequencing data. PLoS One 7(2): e30619, 2012.

28 Rhead B, Karolchik D, Kuhn RM, Hinrichs AS, Zweig AS, Fujita PA, Diekhans M, Smith KE, Rosenbloom KR, Raney BJ, Pohl A, Pheasant M, Meyer LR, Learned K, Hsu F, HillmanJackson J, Harte RA, Giardine B, Dreszer TR, Clawson H, Barber GP, Haussler D and Kent WJ: The UCSC genome browser database: Update 2010. Nucleic Acids Res 38(Database issue): D613-619, 2010.

$29 \mathrm{Li} \mathrm{H}$ and Durbin R: Fast and accurate short read alignment with Burrows-Wheeler transform. Bioinformatics 25(14): 1754-1760, 2009.

30 DePristo MA, Banks E, Poplin R, Garimella KV, Maguire JR, Hartl C, Philippakis AA, del Angel G, Rivas MA, Hanna M, McKenna A, Fennell TJ, Kernytsky AM, Sivachenko AY, Cibulskis K, Gabriel SB, Altshuler D and Daly MJ: A framework for variation discovery and genotyping using next-generation DNA sequencing data. Nat Genet 43(5): 491-498, 2011.

31 Sherry ST, Ward MH, Kholodov M, Baker J, Phan L, Smigielski EM and Sirotkin K: DBSNP: The NCBI database of genetic variation. Nucleic Acids Res 29(1): 308-311, 2001.

32 Cibulskis K, Lawrence MS, Carter SL, Sivachenko A, Jaffe D, Sougnez C, Gabriel S, Meyerson M, Lander ES and Getz G: Sensitive detection of somatic point mutations in impure and heterogeneous cancer samples. Nat Biotechnol 31(3): 213-219, 2013.

33 Wang K, Li M and Hakonarson H: Annovar: Functional annotation of genetic variants from high-throughput sequencing data. Nucleic Acids Res 38(16): e164, 2010.
34 Magi A, Tattini L, Cifola I, D'Aurizio R, Benelli M, Mangano E, Battaglia C, Bonora E, Kurg A, Seri M, Magini P, Giusti B, Romeo G, Pippucci T, De Bellis G, Abbate R and Gensini GF: Excavator: Detecting copy number variants from whole-exome sequencing data. Genome Biol 14(10): R120, 2013.

35 Fujii A, Harada T, Iwama E, Ota K, Furuyama K, Ijichi K, Okamoto T, Okamoto I, Takayama $\mathrm{K}$ and Nakanishi $\mathrm{Y}$ : Hypermethylation of the CPG dinucleotide in epidermal growth factor receptor codon 790: Implications for a mutational hotspot leading to the T790M mutation in non-small-cell lung cancer. Cancer Genet 208(5): 271-278, 2015.

36 Li C, Liu H, Zhang B, Gong L, Su Y, Zhang Z and Wang C: Whole-exome sequencing identifies key mutated genes in T790M wild-type/cMET-unamplified lung adenocarcinoma with acquired resistance to first-generation EGFR tyrosine kinase inhibitors. J Cancer Res Clin Oncol 144(6): 1079-1086, 2018.

37 Masago K, Fujita S, Muraki M, Hata A, Okuda C, Otsuka K, Kaji R, Takeshita J, Kato R, Katakami N and Hirata Y: Nextgeneration sequencing of tyrosine kinase inhibitor-resistant nonsmall-cell lung cancers in patients harboring epidermal growth factor-activating mutations. BMC Cancer 15: 908, 2015.

38 Huang dW, Sherman BT and Lempicki RA: Systematic and integrative analysis of large gene lists using david bioinformatics resources. Nat Protoc 4(1): 44-57, 2009.

39 Stinchcombe TE: Novel agents in development for advanced non-small cell lung cancer. Ther Adv Med Oncol 6(5): 240-253, 2014.

40 Garon EB, Rizvi NA, Hui R, Leighl N, Balmanoukian AS, Eder JP, Patnaik A, Aggarwal C, Gubens M, Horn L, Carcereny E, Ahn MJ, Felip E, Lee JS, Hellmann MD, Hamid O, Goldman JW, Soria JC, Dolled-Filhart M, Rutledge RZ, Zhang J, Lunceford JK, Rangwala R, Lubiniecki GM, Roach C, Emancipator K, Gandhi L: KEYNOTE-001 Investigators: Pembrolizumab for the treatment of non-small-cell lung cancer. N Engl J Med 372(21): 2018-2028, 2015.

41 Schoeberl B, Faber AC, Li D, Liang MC, Crosby K, Onsum M, Burenkova O, Pace E, Walton Z, Nie L, Fulgham A, Song Y, Nielsen UB, Engelman JA and Wong KK: An ERBB3 antibody, MM-121, is active in cancers with ligand-dependent activation. Cancer Res 70(6): 2485-2494, 2010.

42 Gettinger SN, Horn L, Gandhi L, Spigel DR, Antonia SJ, Rizvi NA, Powderly JD, Heist RS, Carvajal RD, Jackman DM, Sequist LV, Smith DC, Leming P, Carbone DP, Pinder-Schenck MC, Topalian SL, Hodi FS, Sosman JA, Sznol M, McDermott DF, Pardoll DM, Sankar V, Ahlers CM, Salvati M, Wigginton JM, Hellmann MD, Kollia GD, Gupta AK and Brahmer JR: Overall survival and long-term safety of nivolumab (anti-programmed death 1 antibody, BMS-936558, ONO-4538) in patients with previously treated advanced non-small-cell lung cancer. J Clin Oncol 33(18): 2004-2012, 2015.

Received December 9, 2018

Revised December 16, 2018

Accepted December 18, 2018 